\title{
Despertando para a vida acadêmica
}

\section{Vanessa Ferreira da Silva}

DOI: https://doi.org/10.31692/978-65-88970-22.20-27

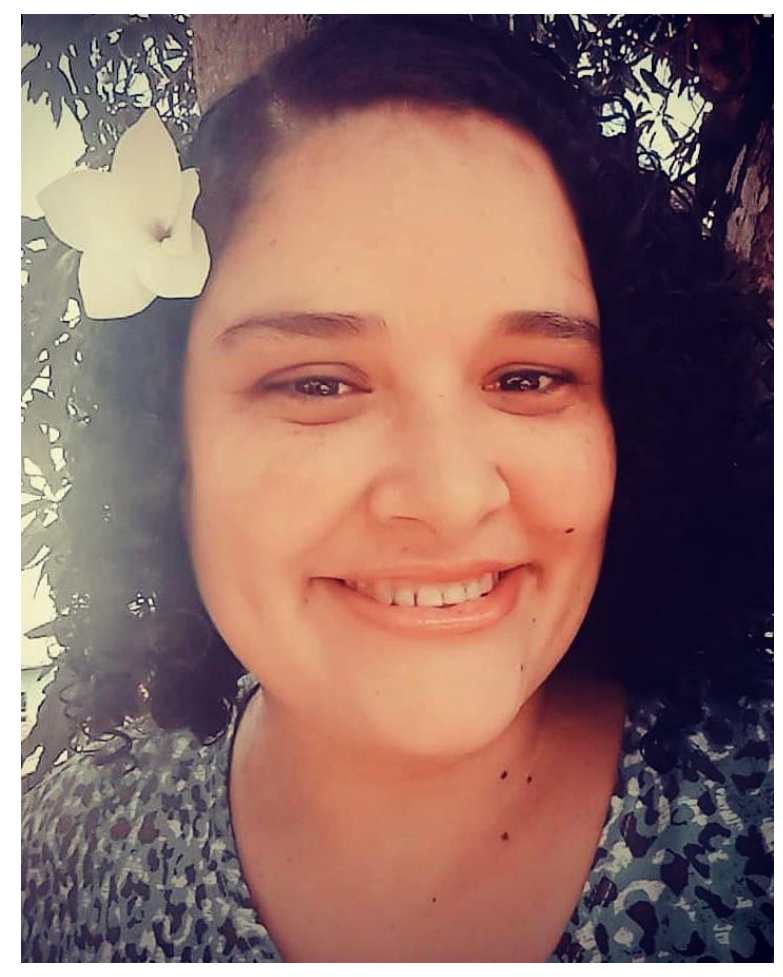

Sou Vanessa Ferreira da Silva, nascida em 25 de janeiro de 1992, tenho 29 anos, sou Recifense e tenho um orgulho danado do meu "país" Pernambuco e desse povo guerreiro e arretado. Nas próximas páginas contarei um pouco sobre minha singela trajetória até chegar neste momento incrível que é fazer parte do PDV.

Fui filha única por quase nove anos, tornando-me, depois disso, a primogênita de três filhos de uma humilde família que reside até hoje em um bairro simples da cidade de Recife, onde a paisagem revela uma mistura de casas e trechos de mata.

Fui uma criança sonhadora e com uma imaginação aguçada, e durante toda a infância, com muita criatividade, transformava o grande quintal de casa em florestas, parques, campo de futebol, mar e escola. Foi no quintal de casa que descobri e aprendi que não precisava de muito para me divertir, as plantas de minha querida mainha eram minhas amigas e companheiras de aventura e foi neste mesmo quintal que plantei minha primeira árvore, uma linda mangueira que dá frutos até hoje.

Sempre fui fascinada em aprender, e aprendi a ler com quatro anos brincando de escola com uma prima que já era alfabetizada, e a partir daí comecei a acompanhar meu pai nas leituras dos jornais, mas só entrei na escola aos cinco anos porque era a idade mínima permitida para ingresso na escola pública. A primeira escola que frequentei foi a Escola Municipal Ministro Marcos Freire em um bairro da periferia de 
Olinda, pois no meu bairro não havia escolas. Estudei no "Ministro" Icomo chamávamos a escolal até meus 14 anos, quando terminei o Ensino Fundamental. Lá me sentia em casa porque a escola tinha um terreno enorme cheio de árvores que me lembravam do quintal de casa.

Durante os 10 anos que estudei no "Ministro" adquiri ainda mais gosto pela leitura, adicionando vários livros, principalmente de literatura brasileira, às minhas leituras diárias no intervalo das aulas. Somei muitos aprendizados com meus queridos professores que foram essenciais para eu dar continuidade aos meus estudos, pois na periferia sobram dificuldades que colaboram para nos desviar do caminho da educação. Assim, meus professores se tornaram uma bússola na minha caminhada, e desde cedo aprendi a absorver todos os bons ensinamentos transmitidos por eles e, com certeza, isso se tornou um diferencial em minha vida.

A escola municipal Ministro Marcos Freire é muito especial para mim, pois lá vivi momentos inesquecíveis de ricos aprendizados que despertaram em mim o desejo gratificante de sempre compartilhar meus conhecimentos. Foram muitas experiências, desde ser representante de turma até presidente do Grêmio Estudantil e representante dos alunos no Conselho de Classe com apenas 13 anos. Além disso, ganhei amizades verdadeiras que duram até hoje, e entre elas destaco a minha querida amiga e eterna professora Jenny Elane, uma excelente professora de Língua Portuguesa, que ainda atua na rede pública estadual.

Entrei no Ensino Médio aos 15 anos, ainda em escola pública, só que agora uma escola pública estadual de um bairro mais distante de casa. Lá encontrei novos desafios. Apesar de ter sempre o incentivo de meus professores no Ensino Fundamental, quando cheguei ao Ensino Médio, não tinha o entendimento de como me preparar para uma futura vida de universitária. Então, com esforço e resiliência superei o impacto de estudar em uma escola diferente e com colegas e professores diferentes, mas continuava sem compreender o caminho que devia trilhar para chegar à universidade. 
No último ano do Ensino Médio na Escola Estadual Luiz Delgado, que fica no centro de Recife, busquei informações e encontrei orientação sobre o que devia fazer para entrar na universidade e iniciar minha tão sonhada vida acadêmica. Foi com a ajuda de alguns colegas de turma e dos professores que descobri que deveria me dedicar ainda mais aos estudos e, se possível, fazer um curso preparatório para poder ingressar com mais rapidez na universidade. Mas, só depois de um ano que eu havia concluído o Ensino Médio foi que consegui convencer meu pai, que na época era apenas um assalariado, a investir quase 10\% do seu salário em um curso preparatório para que eu estivesse bem preparada para o vestibular. Graças a Deus, ao investimento de meu pai e ao meu grande esforço e dedicação, fui aprovada, em 2011, no curso de Jornalismo na Universidade Federal de Pernambuco em Recife. Porém, devido ao pequeno número de vagas, não fui convocada e fiquei na lista de espera.

No mesmo ano, através do Programa Universidade para Todos - PROUNI, fui aprovada com bolsa integral no curso de Administração de Empresas e no curso de Direito, ambos em universidades particulares de Recife e Olinda, respectivamente. $\mathrm{Na}$ inscrição dei preferência ao curso de Administração e foi ele que escolhi para cursar. Esse foi meu primeiro passo rumo à vida acadêmica.

Ingressar na universidade foi uma conquista maravilhosa, fui a primeira da família a fazer um curso superior e isso se tornou uma responsabilidade e tanto. Tornei-me um exemplo para meus irmãos e primos que teriam mais esperança de realizar o sonho de fazer um curso superior.

Em 2012, iniciei o curso de Administração na FACIPE - Faculdade Integrada de Pernambuco que atualmente é a UNIT PE - Universidade Tiradentes. Lá, com gana e muito mais resiliência, comecei a perceber que entrar na universidade era só um degrau da grande escada da vida acadêmica e que a vida acadêmica é uma vida rapadura, é doce, mas também é dura.

$\mathrm{Na}$ universidade, abri minha mente para o saber e me conectei com ensinamentos diversos que contribuem até hoje para meu crescimento pessoal e 
profissional. Com pouco tempo me identifiquei com o curso e já me sentia realizada só de pensar em praticar minha profissão, e como desde o início meus professores continuaram sendo uma inspiração para minha perseverança nessa trajetória.

No final de 2013, com o objetivo de ter experiência profissional, abandonei o emprego de carteira assinada e fui em busca de estágios na área de administração e durante todo o restante do curso consegui estagiar em duas empresas privadas e em dois órgãos públicos. No início de 2014, consegui o primeiro estágio em uma pequena empresa familiar que produzia e vendia materiais de papelaria e escritório. Nessa empresa estagiei na área comercial, mas só estagiei por seis meses porque no sexto mês minha mãe sofreu um AVCH lacidente vascular cerebral hemorrágicol e precisei ajudá-la em sua recuperação. Sendo assim, não pude renovar o contrato com o estágio, mas continuei o curso com constância, foco e resiliência.

Iniciei o segundo estágio após a recuperação de minha mãe em janeiro de 2015 , estagiando na área financeira de outra empresa familiar que oferecia serviço de rastreamento veicular para pessoas físicas e jurídicas, mas só consegui estagiar por três meses, pois fiquei doente e fui hospitalizada para investigação e diagnóstico de uma doença renal que até então eu desconhecia. Foi uma fase difícil, pois parei todas as minhas atividades, inclusive as acadêmicas, saí do estágio, tranquei a matrícula na universidade e no mês de abril fui internada no HUOC - Hospital Universitário Oswaldo Cruz, e posteriormente no IMIP - Instituto de Medicina Integral Professor Fernando Figueira, para um possível diagnóstico. Durante a internação, me aproximei mais de Deus, refleti sobre minha vida pessoal, espiritual, acadêmica e sobre meu futuro incerto. Apesar das incertezas, pela fé, decidi me esforçar e me dedicar muito mais às minhas atividades quando estivesse recuperada e, sobretudo, seguir minha vida acadêmica com mais vigor e destreza. Após trinta dias no hospital, no final de maio de 2015 fiz o último exame (biópsia renal) e recebi alta ainda doente. Voltei para casa e passei os quatro meses seguintes sem poder fazer esforços físicos e sem sair por conta da síndrome nefrótica que causa edema generalizado (inchaço). 
No final de setembro do mesmo ano recebi o resultado da biópsia que acusava lesões mínimas (cicatrizes) nos rins, e segundo a nefrologista isso indicava o início de uma doença renal que se chama GESF - glomerulosclerose segmentar focal. Apesar de não ter cura, a doença tem tratamento e pode ser controlada. Segui o tratamento e no início de 2016 pude retornar à universidade e às minhas atividades, mas com cuidado, pois ainda estava em tratamento.

Em janeiro de 2016 fui convocada pelo TRF5 - Tribunal Regional Federal da $5^{a}$ Região para estagiar e com muita gratidão comecei o ano com alegria e imenso desejo de aprender. Esse estágio que foi muito especial para mim, durou dois anos (20162018) e me proporcionou novas experiências e a oportunidade de praticar o que eu aprendia na universidade. No TRF5 estagiei na Diretoria Geral (DG) e tive como exemplos de liderança mulheres que muito admiro e que me ensinaram direta ou indiretamente muitas lições, como por exemplo, a Diretora Geral da época, a Desembargadora Margarida Cantarelli que com gentileza, delicadeza e sabedoria transmitia seu conhecimento com muita empatia, sempre demonstrando orgulho por também ser professora, pois ainda ensinava na época.

Quando finalizei o estágio no TRF5 fui chamada para estagiar no TCE PE Tribunal de Contas do Estado. Nesse estágio, que durou pouco mais de um ano, convivi com pessoas que também me ensinaram muito do que sei hoje e contribuíram para meu amadurecimento profissional. Foi uma boa experiência que findou em junho de 2019, quando terminei o curso de Administração.

No último semestre do curso de Administração, estudei uma disciplina chamada Gestão Ambiental e despertei o interesse de aprofundar meu conhecimento na área. Então, busquei pós-graduações em Gestão Ambiental, mas como só encontrei em instituições privadas não consegui cursar por falta de recursos financeiros.

Felizmente, ainda em 2019, descobri que o Instituto Federal de Pernambuco (IFPE), Campus Recife, ofertava o curso Tecnólogo em Gestão Ambiental e logo me inscrevi no processo seletivo, conseguindo uma vaga para iniciar o curso no segundo 
semestre. Estava muito contente por já ser graduada, mas sentia que me faltava a experiência em projetos acadêmicos, como participar de programas de pesquisa, extensão e monitoria, o que na faculdade de Administração não tive oportunidade de fazer por conta da limitada oferta desses programas.

No primeiro dia de aula no IFPE, dia 29 de julho de 2019, tive uma excelente aula da disciplina de Metodologia da Pesquisa Científica com duas docentes inesquecíveis, professoras doutoras Paula Cordeiro e Elba Ferraz, que com maestria me encantaram ao falar de pesquisa científica e das possíveis experiências acadêmicas que todos nós da turma poderíamos ter. Logo, surgiu o enorme desejo de vivenciar essas experiências e aproveitar a vida acadêmica em sua totalidade. Como não sabia nada sobre o assunto, nas aulas seguintes procurei as professoras para saber sobre como poderia entrar em projetos de pesquisas e/ou extensão, e elas, com muita paciência, me esclareceram sobre o assunto e ainda me incentivaram a ficar atenta aos editais que seriam lançados. Daí comecei a pesquisar sobre editais, projetos e grupos de pesquisas relacionados e/ou vinculados ao curso de Gestão Ambiental.

No final de agosto de 2019, o IFPE lançou o edital para o Programa BIA - Bolsas de Incentivo Acadêmico, e então procurei a professora Elba Ferraz para saber de sua disponibilidade para submeter um projeto de pesquisa e me orientar no programa, no caso de ser aprovado, pois me identifiquei com sua área de atuação. Fui bem recebida pela professora, que me incentivou a pensar e elaborar um projeto de pesquisa dentro da minha área de interesse. Isso foi muito importante para meu desenvolvimento como aluna pesquisadora.

Apesar da minha falta de experiência, consegui elaborar um esboço do projeto de pesquisa que intitulei como “A Educação Ambiental atuando como instrumento de conscientização ecológica para a sustentabilidade e conservação da Reserva de Floresta Urbana Mata do Passarinho", que posteriormente foi aperfeiçoado pela professora Elba, que aceitou me orientar e submeteu o projeto ao edital BIA. No início 
de setembro daquele mesmo ano, quando estava finalizando o primeiro semestre do curso, o projeto foi aprovado e comecei com muita alegria minha primeira pesquisa científica (2019 a 2020), sendo bolsista da Fundação de Amparo a Ciência e Tecnologia do Estado de Pernambuco (FACEPE).

O programa BIA foi o pontapé inicial para o desenvolvimento e despertar da minha vida acadêmica no IFPE. Depois disso, solicitei à minha orientadora que submetesse outro projeto de pesquisa para que eu pudesse continuar desenvolvendo meu conhecimento científico. Assim, consegui uma bolsa de pesquisa do PIBIC Programa Institucional de Bolsas de Iniciação Cientifica, como bolsista do IFPE. Essa nova pesquisa foi voltada para o estudo da vegetação e foi intitulada "Vegetação da Reserva de Floresta Urbana - Furb Mata de Passarinho: Conhecer para Proteger, Manejar e Educar" e foi concluída no mês de setembro de 2021.

Atualmente, já estou realizando outra pesquisa PIBIC, agora como bolsista do Conselho Nacional de Desenvolvimento Científico e Tecnológico (CNPq). Nessa pesquisa, mais uma vez, minha queridíssima orientadora me deu a oportunidade de poder colaborar na elaboração do projeto que relaciona ferramentas da administração com a gestão ambiental. A pesquisa tem por título “Aplicabilidade da matriz GUT na análise das principais perturbações antrópicas de uma unidade de conservação urbana" e se apresenta como mais uma maravilhosa experiência na minha vida acadêmica.

Além de fazer pesquisa científica, também participo como voluntária do programa de monitoria, onde fui por três semestres consecutivos monitora da disciplina de Ecologia, tendo também como orientadora a professora Elba Ferraz que me orienta desde a primeira pesquisa e acreditou no meu potencial desde o início, se tornando minha mentora e uma grande referência e inspiração por ser um excelente exemplo de pessoa, professora e profissional.

Diante de tantas experiências boas, não imaginava que era possível agregar ainda mais valor à minha vida acadêmica e profissional. Mas, ao conhecer o Programa 
Internacional Despertando Vocações (PDV), percebi que o céu não é o limite e que adquirir conhecimento nunca é demais.

Em plena pandemia, em junho de 2020, fui convidada pelo professor e grande mestre Erick Viana, professor do IFPE Campus Recife, para participar de uma reunião onde o PDV seria apresentado a um grupo de estudantes de várias instituições de ensino superior, incluindo o IFPE. Sem pretensão de nada, pois não conhecia o PDV, participei da reunião e fiquei encantada com a beleza contida nos trabalhos desenvolvidos pelos PDVs, que trabalham o ensino, pesquisa, extensão e gestão em diferentes áreas. Logo que o convite para participar foi feito eu aceitei e entrei no Programa Internacional Despertando Vocações para a Gestão (PDVG) e essa foi, sem dúvida, uma das decisões mais certas que tomei na vida.

No PDVG, participo do projeto de extensão para a criação de Empresa Júnior em diversos campi do IFPE, projeto que foi iniciado no Campus Recife onde estudo. Também faço parte do grupo de trabalho de empreendedorismo onde aprendo muito com excelentes profissionais e professores da área de Administração, incluindo o querido professor Erick Viana que também se tornou meu mentor nessa belíssima trajetória dentro do PDV.

Vale ressaltar, que meu despertar para a vida acadêmica foi potencializado dentro do PDV e sinto que minha vocação para docência também foi despertada. Hoje tenho certeza que quero seguir carreira acadêmica. Desejo ensinar, transmitir e compartilhar todo o conhecimento e experiências que adquiri, além de incentivar mais pessoas a seguirem e perseverarem na vida acadêmica.

Sou grata a Deus por fazer parte do PDV, e agora somo muito mais experiências, conhecimentos e vivências inesquecíveis que vou levar para toda a vida, graças às oportunidades proporcionadas pelo PDV que, com certeza, tem contribuído e muito para meu crescimento profissional e pessoal. 